E-MAIL CONTRIBUTIONS

\title{
Fund fewer PhDs and give youngsters a realistic picture of their future
}

\section{JUNE GRAHAM}

I completed my first postdoc a month ago and have been trying since January, so far unsuccessfully, to obtain further employment in the sciences. As MaryLou Pardue and colleagues say, it is impossible, looking at one case, to determine whether gender discrimination is a factor. From my own experience, I think that obtaining scientific funding is difficult for any young scientist, male or female, but I am left with the niggling question as to whether it would have been easier if I was a man.

I'm pleased I received encouragement at school when my interest in science was discovered. In fact, a picture was painted of a glittering future for female scientists. Perhaps it would be been wise, given the difficulties in obtaining scientific funding, to present young hopefuls with a realistic picture - rather than going in for the hard sell.

But it didn't take much encouragement to put me on the first steps of a scientific career. I worked extremely hard, leaving university with a first class degree, and a number of prizes and scholarships. An MSc and a PhD followed, and I continued to dedicate a great deal of time and energy to my work. During this time, I encountered no discrimination on the basis of my gender. Although I felt, at times, a little discouraged by the lack of female role models in lectureship and research positions.

After my $\mathrm{PhD}$, I took up a short postdoc at the same university. In the short term, I wanted to stay at the same institution because my husband was working nearby. I had no doubts, based on my previous success in obtaining scholarships, that when we were both ready to move on, I would be able to find work elsewhere. Since my husband does not have a $\mathrm{PhD}$, he let me to take the career lead - a situation which seemed to be ideal for a young female scientist. All I needed was a job. However, when I began applying for advertised posts the response (or lack of it) was crushing. Since January, I have been short-listed for only one job. In many cases, I didn't even receive an acknowledgement of my application.

Naturally I have asked myself why my career has ground to a sudden and unexpected halt. I have wondered whether my qualifications and experience are at fault. Talking with other scientists has reassured me my CV is good, and that it is currently difficult for any young scientist to obtain post-doctoral funding. Having a partner's career to consider compounds these difficulties and it is probable that being a woman, particularly a married woman of childbearing age, makes matters worse.

As noted by Gene A. Nelson, there is a glut of qualified scientists. That is good for employers who can pick the best and discard the rest. However, it means that many of us are going to have dedicated crucial years to starting a career that leads to a dead end. When there are relatively few qualified candidates, an employer will choose a female candidate whose qualifications outshine those of male colleagues. But if there is a choice of several outstanding scientists, both male and female, is it surprising that an employer will choose a man over an equally qualified woman, who may be costly in terms of maternity leave?

Many appointments are offered on an initial basis of one year or even less. This may be fine if you are single and are prepared to use a short termjob as a stepping stone to another job in yet another place. This is difficult for a couple. I am still holding our hope of obtaining a fellowship from a funding 
body. If I am unable to obtain a research position, my prospects are bleak.

Perhaps the government should consider funding fewer $\mathrm{PhD}$ positions, and allow those who are funded to receive a decent remuneration rather than the current subsistence level stipend which many receive. Fewer $\mathrm{PhDs}$ would mean that women with $\mathrm{PhDs}$ would have a better chance at obtaining a research position. Those who were unsuccessful in obtaining $\mathrm{PhD}$ funding in a more competitive system could use these crucial years to build up careers outside the academic system. This is particularly important for women who want to establish themselves in a career and achieve some measure of stability before having children. Of course this would only help female scientists if they did not experience increasing discrimination as the system of $\mathrm{PhD}$ funding became more competitive.

June Graham

Aberdeen, Scotland

EGr7967034@aol.com

Nature @ Macmillan Publishers Ltd 1999 Registered No. 785998 England. 